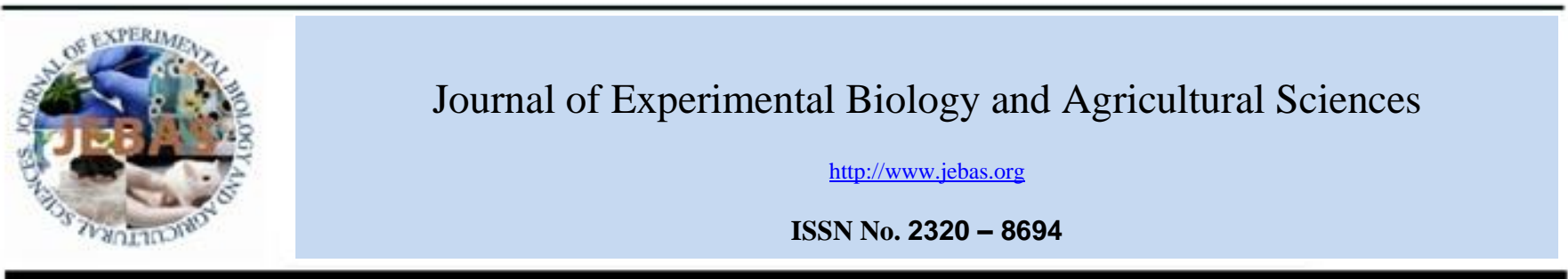

\title{
ANTIFUNGAL ACTIVITY OF CHITOSAN AGAINST Rhizopus stolonifer
}

\author{
Khawlah Abdallah Salman ${ }^{1 *}$, Hussein Ali Hussein ${ }^{2}$, Saddam Hussein Abbas ${ }^{3}$ \\ ${ }^{1,2}$ Department of Food Sciences, Faculty of Agriculture, University of Kufa, Al-Najaf, Iraq 540011 \\ ${ }^{3}$ Department of Field Crops, Faculty of Agriculture, Al-Qasim Green University, Iraq 51013
}

Received - November 13, 2021; Revision - December 20, 2021; Accepted - December 29, 2021

Available Online - December 30, 2021

DOI: http://dx.doi.org/10.18006/2021.9(6).901.906

\section{KEYWORDS}

Rhizopus stolonifer

Soft rot

Tomato

Chitosan

Antifungal activity

\begin{abstract}
These days instead of chemical pesticides, various natural alternatives have been used for the management of post-harvest diseases. This research was carried out to evaluate the antifungal potential of different chitosan concentrations viz., 5, 10, and $15 \mathrm{mg} / \mu$ l against Rhizopus stolonifer by the agar dilution and well diffusion methods. The evaluation was carried out after seven days of incubation by measuring the inhibition of $R$. stolonifer mycelial growth. Results of the study revealed that the chitosan had a significant inhibitory effect on mycelial growth and maximum mycelial growth inhibition was reported at the 10 and $15 \mathrm{mg} / \mu \mathrm{l}$ concentrations and these two treatments are not significantly different. Based on these results, the best concentration $(15 \mathrm{mg} / \mu \mathrm{l})$ was further evaluated by the well diffusion technique. The average inhibition zones formed by the higher concentration was $25 \mathrm{~mm}$. Results of the study suggested that chitosan can be used for the management of post-harvesting diseases of tomatoes.
\end{abstract}

* Corresponding author

E-mail: khawla.alzurfi@uokufa.edu.iq (Khawlah Abdallah Salman)

Peer review under responsibility of Journal of Experimental Biology and Agricultural Sciences.

Production and Hosting by Horizon Publisher India [HPI] (http://www.horizonpublisherindia.in/).

All rights reserved.
All the articles published by Journal of Experimental Biology and Agricultural Sciences are licensed under a Creative Commons Attribution-NonCommercial 4.0 International License Based on a work at www.jebas.org.

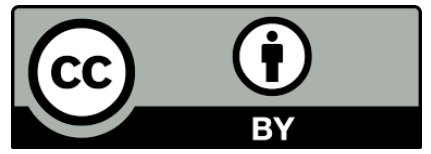




\section{Introduction}

Chitosan is a homogeneous biopolymer composed of repeating units of glucosamine and derived from chitin. It is an essential component of the exoskeleton of crustaceans, insects, and fungal cell walls (Goy et al., 2009, Beliaeva et al., 2020). Commercial formation of chitosan is a multistep procedure that includes deproteinization, demineralization, depigmentation, and finally partial or complete removal of the acetyl group (Pakizeh et al. 2021). Chitosan has various medicinal properties and the effectiveness of Chitosan as an anti-tumor agent and elements that lower blood cholesterol levels have been well established. It also can retain water and lipids, dyes, stabilizing emulsions, forming gels, and chelating agents (Elsabee \& Abdou 2013).

In recent years, there has been a lot of interest in chitosan applications in food processing, nutrition, chemical engineering, pharmaceutical manufacturing, and environmental protection (Bibi et al., 2021). Chitosan has strong antimicrobial activity, and its antimicrobial activity is dependent on molecular weight, degree of acetyl group elimination, $\mathrm{pH}$, and microorganism type (Chien et al., 2016), it is known that polymer characteristics can influence the functional properties of systems where is added (Goy et al., 2009). Chitosan can inhibit the growth of many fungi because it stimulates the production of chitinases. Chitinase acts on the chitin of the fungal cell wall render the fungi inactive without any negative impact on the plant and enhancing the shelf life of the plant (Kumar et al., 2018). Therefore, the damage caused by fungi can be controlled by the stimulation of defense enzymes (Chien et al., 2016; Meng et al., 2020). Some authors have found that chitosan affects mycelial growth and causes severe damage to the hyphae, and other morphological structures of fungi (Singh \& Sharma 2007; Alfaro-Sifuentes et al., 2019; Bibi et al., 2021). Additionally, it permeabilized and penetrated the plasma membrane of different fungal cells (hyphae, spores, and tube germ cells), suggesting that the polymer interacted with external membrane components, causing structural changes that involved pore formation (Lin et al., 2020). Other investigations showed that proteins and other intracellular constituents come out from these pores and fungal pathogens become inactive (Guo et al., 2006).

Fruit and vegetable spoilage caused by microorganisms is common during the storage and transportation of agricultural products at the stage of postharvest (Devlieghere et al., 2004; Al-Najada \& Gherbawy, 2015). Chitosan can be used as a natural alternative to control postharvest rot diseases of horticultural products caused by different fungi (Lin et al., 2020). Chitosan is well known for its ability to kill many microorganisms that spoil food, including bacteria, fungi, and yeasts (Goy et al., 2009). Hence, the formation of chitosan-natural, edible film coating material is an important step for preserving food from fungi spoilage (Meng et al., 2020). El Ghaouth et al. (1992) applied chitosan coating for protecting tomatoes from infection of Penicillium spp., Aspergillus spp., Rhizopus stolonifer, and Botrytis cinerea and found a significant effect on the management of post-harvest disease caused by these pathogens. Similarly, Romanazzi et al. (2017) reported that coatings of calcium chloride (2\%) with chitosan on papaya fruits (Carica papaya L.) reduce $20 \%-30 \%$ post-harvest loss and increase the shelf life of papaya. Further, chitosan can be used for enhancing the quality and extending the shelf life of many food items obtained from plants, animals, marine sources, and processed foods is well (Elsabee \& Abdou, 2013).

$R$. stolonifer is considered as one of the main phytopathogens that cause soft rot disease, which leads to cellular maceration of tissues and causes significant economic losses. It is estimated that up to $30 \%$ of tomato crops are lost due to $R$. stolonifer before they reach the consumer (Bautista-Baños et al., 2014). This study aims to analyze the antifungal activity of chitosan to inhibit the growth of $R$. stolonifer and determine the effective inhibition concentration.

\section{Materials and Methods}

\subsection{Materials}

Tomatoes showing signs of spoilage and damage were collected from the local market in Najaf, Iraq (Figure 1). These samples were transported to the laboratory for isolation of fungal diseasecausing pathogens, for this, rotten areas of the tomato fruit were separated by using a sterilized sharp blade. The separated diseased parts were inoculated on the PDA medium and all Petri plates were incubated 3-7 days at $25-28{ }^{\circ} \mathrm{C}$ temperature in an incubator and fungal growth was regularly monitored.

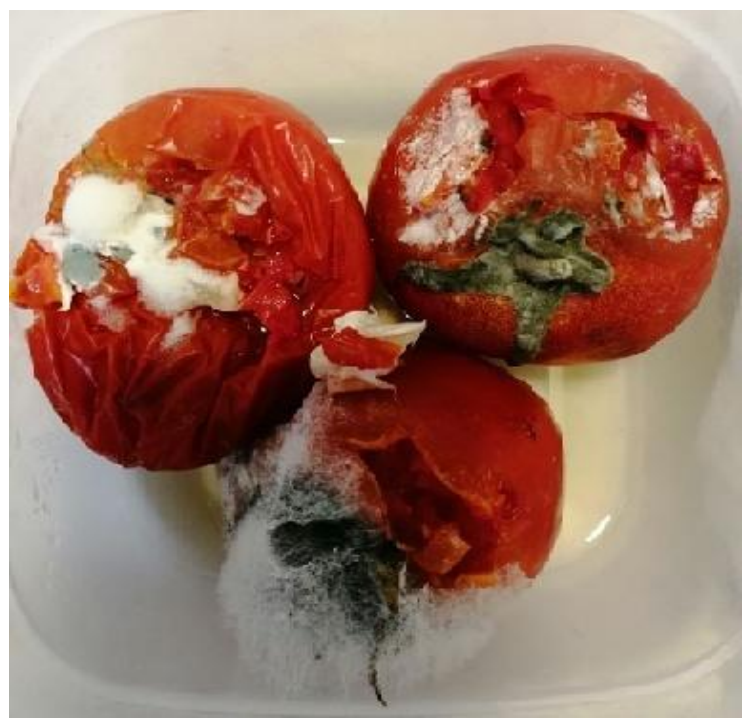

Figure 1 Tomato fruit exhibited soft rot spoilage signs 


\subsection{Preparation of Chitosan solutions}

Chitosan was obtained from Professor Al-mudafer, laboratory of Agriculture, Kufa University as the product derived from Agaricus bisporus (Figure 2). The stock solution of the chitosan was prepared by dissolving two grams of chitosan in $100 \mathrm{ml}$ of distilled water with $2 \mathrm{ml}$ of acetic acid and stirred for $24 \mathrm{hrs}$. Subsequently, the $\mathrm{pH}$ of the solution was adjusted to 5.6 and corresponding aliquots were taken to prepare the three predefined chitosan concentrations i.e. 5, 10, and $15 \mathrm{mg} / \mu \mathrm{l}$ (Al- Mahmood \& AlMudhaffar, 2021).

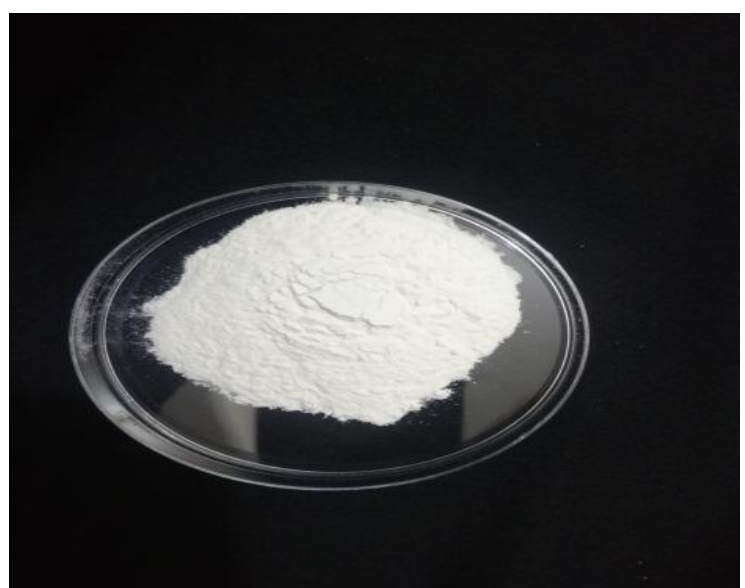

Figure 2 Chitosan derived from Agaricus bisporus

\subsection{Estimation of Chitosan Antifungal activity by agar dilution} method

Initially, pure culture of the distinctive fungal colonies was obtained from the culture isolated from the infected tomato on PDA plates. This was followed by the morphological characterization of the isolated pure culture colonies of $R$. stolonifer, and from this pure culture, $6 \mathrm{~mm}$ mycelium discs were separated and inoculated in the center of Petri dishes having untreated sterilized solid PDA medium and these plates were considered as control plates. While in the case of treatments, PDA medium was supplemented by different predefined chitosan concentrations $(5 \mathrm{mg} / \mu \mathrm{l}, 10 \mathrm{mg} / \mu \mathrm{l}$, and $15 \mathrm{mg} / \mu \mathrm{l})$, and a $6 \mathrm{~mm}$ disc of freshly cultured $R$. stolonifer was placed in the center of each Petri plate. A plate with $1 \%$ acetic acid had been considered as a negative control. All these Petri plates were incubated at $25-28^{\circ} \mathrm{C}$ for 7 days and the average inhibition zone of three replicates was calculated in $\mathrm{mm}$ and compared with the mycelium growth of untreated Petri plates (without chitosan). All experiments were accomplished in triplicate and repeated three times $(n=9)$.

\subsection{Establishment of Chitosan Antifungal activity by well diffusion method}

Petri plates were inoculated with $100 \mu$ of the spore suspension to make the lawns of fungus on agar until solidified. The well diffusion technique was used to establish the fungal sensitivity of chitosan solution at the predefined concentration. Briefly, the agar plate surface was inoculated by spreading a volume of fungal inoculum over the entire surface (Magaldi et al., 2004). Using a sterile cork borer, a hole with a diameter of $6 \mathrm{~mm}$ was prepared aseptically and $100 \mu \mathrm{l}$ of the chitosan solution with selected concentrations was filled into the well. These agar plates were incubated at $25-28^{\circ} \mathrm{C}$ for 7 days and the diameter of the inhibition zone was measured for the treated plates. The average inhibition zone of three replicates was expressed in mm. All experiments were accomplished in triplicate and repeated three times $(n=9)$.

\subsection{Statistical analysis}

The data was analyzed to find the difference between the three concentrations. One-way ANOVA $(\mathrm{P} \leq 0.05)$ was carried out to demonstrate statistical difference using the average of zones of inhibition.

\section{Results}

Figure 3 shows the colony characteristics and various microscopical characteristics such as colony color, color of spores, sporangiophores size, sporangia shape, and columella size of the

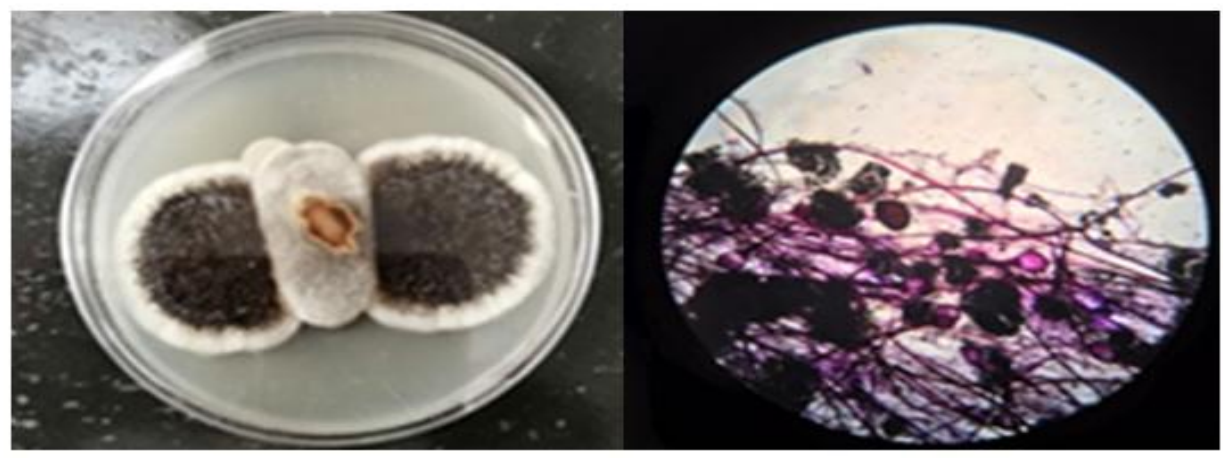

Figure 3 Colony characteristics of R.stolonifer growing on PDA plate (left), microscopic characteristics of the sporangiophores, and sporangia (right).

Journal of Experimental Biology and Agricultural Sciences http://www.jebas.org 
fungal pathogen $R$. stolonifer which was isolated from the tomato fruit showing soft rot disease symptoms. These results are confirmed by the findings of Kwon et al. (2001).

\subsection{The antifungal activity of chitosan in agar dilution method}

The result of the inhibitory effect of chitosan on the growth of $R$. stolonifer revealed that with increasing chitosan concentration size of the inhibition zone also increase which is showing a reduction in the colony growth. Among the tested concentrations, maximum inhibition in mycelium growth was reported at the highest concentration of $15 \mathrm{mg} / \mu \mathrm{l}$ in comparison with the control (Figure 4).

Table 1 Effect of chitosan application of the mycelium growth of R. stolonifer.

\begin{tabular}{|cc|}
\hline Concentration & Zone of inhibition $(\mathrm{mm})$ \\
\hline $5 \mathrm{mg} / \mathrm{ml}$ & $17.67 \pm 2.71^{\mathrm{a}}$ \\
\hline $10 \mathrm{mg} / \mathrm{ml}$ & $21.00 \pm 2.15^{\mathrm{b}}$ \\
\hline $5 \mathrm{mg} / \mathrm{ml}$ & $25.33 \pm 2.95^{\mathrm{c}}$ \\
\hline Control $(1 \%$ acetic acid $)$ & $3.52 \pm 0.65^{\mathrm{d}}$ \\
\hline LSD $(0.05)$ & 0.974 \\
\hline
\end{tabular}

Given values are the average of three replicates; mean \pm SE value followed by the different letter in same vertical column are significantly different according to AVOVA (LSD $=0.05$ ).

\subsection{Antifungal activity of chitosan by agar well diffusion}

For confirming the antifungal activity of chitosan, all the selected doses of chitosan were again assayed by the well diffusion method against the $R$. stolonifer and results showed a similar effect to the agar dilution method. The mean of the inhibition zone diameter is increased with the gradual increase in the concentration. As shown in Table 1 highest concentration $(15 \mathrm{mg} / \mu \mathrm{l})$ has the maximum inhibition zone diameter $(25 \mathrm{~mm})$ was recorded as the most effective concentration on fungal growth.

\section{Discussion}

Results of the present study suggested a significant inhibition efficiency of chitosan against $R$. stolonifer isolated from spoiled tomatoes. Further, from the results of the study it can be suggested that the inhibitory effect of chitosan is dose-dependent and it increases with increasing the concentration of chitosan. These results are similar to the findings of Lin et al. (2020), and Bibi et al. (2021). Further, both methods viz., agar dilution and well diffusion revealed a significant inhibition zone at the concentration of $15 \mathrm{mg} / \mu \mathrm{l}$ and this inhibition zone is greater than the inhibition zone observed at the remaining two concentrations $(\mathrm{P} \leq 0.05)$. These results are comparable with the findings of Meng et al. (2020), those who reported a similar inhibitory effect of chitosan on the growth of Trichoderma harzianum, and this was increased with increasing concentration. The growth stage at which chitosan

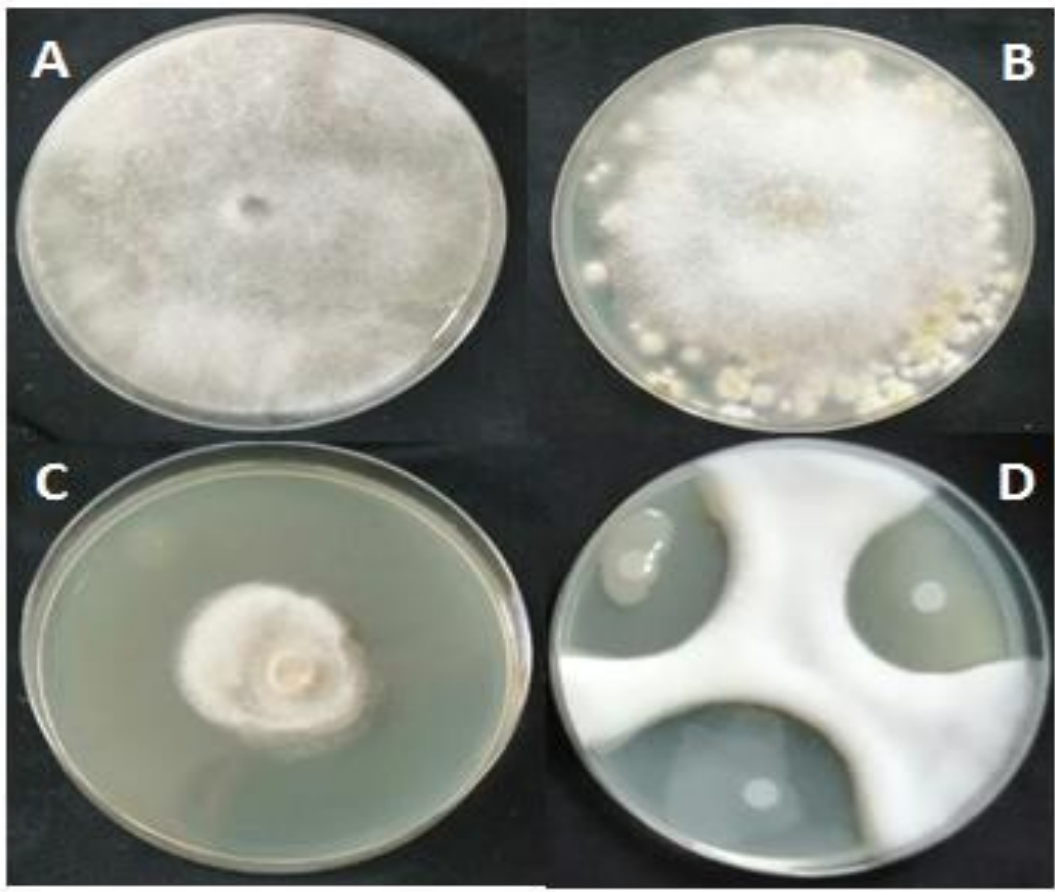

Figure 4 Growth of $R$. stolonifer mycelium on PDA media after seven days of incubation: A - Negative control (1\% acetic acid); B - media treated with $10 \mathrm{mg} / \mu \mathrm{l}$ chitosan; C - media treated with $15 \mathrm{mg} / \mu \mathrm{l}$ chitosan; D - Mycelia were inhibited using a disc saturated with $15 \mathrm{mg} / \mu 1$ concentration 
can be effective varies from one organism to another and it might be due to the components that make up each of these stages to a greater or lesser extent (García et al. 2010; Ing et al., 2012). Furthermore, the antifungal activity could be due to the presence of phenolic compounds that activate or increase when chitosan is added (Bozoğlan et al., 2020).

The current study established the biocidal potential of chitosan against $R$. stolonifer and reported that the application of this natural fungicide can enhance the shelf life of tomato fruits. Due to its non-toxicity, biodergardable, and organic nature chitosan derivatives have been successfully used for the management of fungal diseases and enhancing fruit self-life (Cheng et al., 2014). Various previous studies also established the antifungal activity of chitosan against $R$. stolonifer (Zhang et al., 2011; Lin et al., 2020). Similarly, Liu et al. (2008) and Hernández-Lauzardo et al. (2012), reported the effective inhibitory activity of chitosan against the tomato fruits soft rot disease-causing pathogen $R$. stolonifer and suggested that due to high molecular weight chitosan can significantly inhibit the growth of $R$. stolonifer. Further, previous studies suggested that the application of chitosan disrupted the cell wall of $R$. stolonifer, and at higher concentrations, it can lysis the complete fungal cell (García et al., 2010; Hernández-Lauzardo et al., 2011). Besides, Alburquenque et al. (2010) suggested that due to the positive charge on chitosan, it can modify the cell wall of the mold and interrupt the growth. The interaction of chitosan with different types of fungi depends on the composition of the cell wall, and when the reaction occurs, the polymer interferes with the growth of the fungus. Further, some previous research also suggested that chitosan molecules may diffuse within the hyphae and may interfere with enzymes involved in the growth of fungi (Kong et al., 2010; Zhang et al., 2015; Bibi et al., 2021).

\section{Conclusion}

Results of this study suggested the inhibitory effect of chitosan against the $R$. stolonifer, which is the main cause of the soft rot disease of tomatoes. The application of chitosan can be a promising alternative due to its biocompatible features, adaptability, non-toxicity, and biodegradability. However, further investigations are required to develop edible coating films for longer storage.

\section{Acknowledgements}

The authors did not receive any financial funding from an external body but are grateful to the university authorities for providing research facilities.

\section{Conflict of Interest}

The authors declare there are no competing interests.

\section{References}

Al- Mahmood H, Al-Mudhaffar A (2021) Studying the functional properties of wrappers manufactured from different concentration of chitosan extracted from Agaricus bisporus stems and coated soft cheese. Indian journal of Ecology 48: 1-10.

Alburquenque C, Bucarey S, Neira-Carrillo A, Urzúa B, Hermosilla G, Tapia C ( 2010) Antifungal activity of low molecular weight chitosan against clinical isolates of Candida spp. Medical Mycology 48:1018-1023.

Alfaro-Sifuentes J, Meca E, Valenzuela A ( 2019) Effectiveness of Chemical and Thermal Treatments on Control Rhizopus stolonifer Fruit Infection Comparing Tomato Cultivars with Different Sensitivities to Cracking. International Journal of Environmental Research and Public Health 16: 2754- 2764.

Al-Najada A, Gherbawy Y (2015) Molecular Identification of Spoilage Fungi Isolated from Fruit and Vegetables and Their Control with Chitosan. Food Biotechnology 29:166-184.

Bautista-Baños S, Bosquez-Molina E, Barrera-Necha L (2014) Rhizopus stolonifer (Soft Rot). In: Bautista-Baños S (Ed.) Postharvest Decay Control Strategies; Elsevier Academic Press: San Diego, CA, USA Pp. 1- 44.

Beliaeva A, Nianikova G, Rostovtseva P (2020) Chitin-chitosan complex from Rhizopus oryzae obtained on a pea culture medium, and some of its physicochemical properties. E3S Web of Conferences 215:06001.

Bibi A, Mareena I, Shalmani A, Rehan T, Quratulain A (2021) A review on recent advances in chitosan applications. Pure and Applied Biology 4:1217-1229.

Bozoğlan B, Duman O, Tunç S (2020) Preparation and characterization of thermosensitive chitosan/carboxymethyl cellulose/scleroglucannano composite hydrogels. International Journal of Biological Macromolecules 162: 781-797.

Cheng L, Wu T, Wang J, Wu, Chung M, Kuo Y, Tsai CH (2014) Production and isolation of chitosan from Aspergillus terreus and application in tin (II) adsorption. Journal of Applied Polymer Science 131: 40436- 40436.

Chien R, Yen M, Mau J (2016) Antimicrobial and antitumor activities of chitosan from shiitake stipes, compared to commercial chitosan from crab shells. Carbohydrate Polymers 138: 259-264.

Devlieghere F, Vermeulen A, Debevere J (2004) Chitosan: antimicrobial activity, interactions with food components and applicability as a coating on fruit and vegetables. Food Microbiology 21: 703-714. 
El Ghaouth A, Ponnampalam R, Castaigne F, Arul J (1992) Chitosan coating to extend the storage life of tomatoes. Hor Science 27 :1016-1018.

Elsabee M, Abdou E (2013). Chitosan based edible films and coatings: A review. Materials Science and Engineering: C 33 1819-1841.

García-Rincón J, Vega-Pérez J, Guerra-Sánchez MG, HernándezLauzardo AN, Peña-Díaz A, Velázquez-Del Valle MG (2010) Effect of chitosan on growth and plasma membrane properties of Rhizopus stolonifer (Ehrenb.:Fr.) Vuill. Journal of Pesticide Biochemistry and Physiology 97:275-278.

Goy R, Britto A, Assis O (2009) A review of the antimicrobial activity of chitosan. Polímeros 19: 241247.

Guo Z, Chen R, Xing R, Liu S, Yu H, Wang P, Li C, Li P( 2006) Novel derivatives of chitosan and their antifungal activities in vitro. Carbohydrate Research 341:351-354.

Hernández-Lauzardo A, Guerra-Sánchez M, Vega-Pérez J, Velázquez-del Valle M (2012) Assessment of the effect of chitosan of different molecular weights in controlling Rhizopus rots in tomato fruits. Archives of Phytopathology and Plant Protection 45:33-41.

Hernandez-Lauzardo A, Miguel G, Maria G ( 2011) Current status of action mode and effect of chitosan against phytopathogens fungi. African Journal of Microbiology Research 5: 4243-4247.

Ing LY, Zin NM, Sarwar A, Katas H (2012) Antifungal activity of chitosan nanoparticles and correlation with their physical properties. International Journal of Biomaterials 5: 632698. doi 10.1155/2012/632698.

Kong M, Chen X, Xing K, Park A (2010) Antimicrobial properties of chitosan and mode of action: A state of the art review. Journal Food Microbialogy 144 : 51-63.

Kumar M, Brar A, Yadav M, Chawade A, Vivekanand V, Pareek N (2018) Chitinases-Potential Candidates for Enhanced Plant Resistance towards Fungal Pathogens. Agriculture 8: 88-98.
Kwon J, Kang S, Kim J, Park C (2001) Rhizopus Soft Rot on Cherry Tomato Caused by Rhizopus stolonifer in Korea. Mycobiology 29:176-178.

Lin F, Huang Z, Chen Y, Zhou L, Chen M, Sun J, Lu Z, Lu Y ( 2020) Effect of combined Bacillomycin $D$ and chitosan on growth of Rhizopus stolonifer and Botrytis cinerea and cherry tomato preservation. Journal of the Science of Food and Agriculture 101:229-239.

Liu P, Piao XS, Kim SW, Wang L, Shen YB, Lee HS, Li SY (2008) Effects of chito-oligosaccharide supplementation on the growth performance, nutrient digestibility, intestinal morphology, and fecal shedding of Escherichia coli and Lactobacillus in weaning pigs. Journal of Animal Science 86 (10): 2609-2618.

Magaldi S, Mata-Essayag S, Hartung D, Capriles C (2004) Well diffusion for antifungal susceptibility testing. Journal of the Infectious Diseases 8:39-45.

Meng D, Garba B, Ren Y, Yao M, Xia X, Li M, Wang Y (2020) Antifungal activity of chitosan against Aspergillus ochraceus and its possible mechanisms of action. International Journal of Biological Macromolecules 158: 1063-1070.

Pakizeh M, Moradi A, Ghassemi T ( 2021) Chemical extraction and modification of chitin and chitosan from shrimp shells. European Polymer Journal 159: 110718-110709.

Romanazzi G, Feliziani E, Baños S (2017) Shelf life extension of fresh fruit and vegetables by chitosan treatment. Critical Reviews in Food Science and Nutrition 57: 579-601.

Singh D, Sharma RR (2007) Postharvest diseases of fruit and vegetables and their management. In: Prasad D (Ed) Sustainable Pest Management. New Delhi: Daya Publishing House.

Zhang D, Wang H, Hu Y, Liu Y ( 2015) Chitosan Controls Postharvest Decay on Cherry Tomato Fruit Possibly via the Mitogen-Activated Protein Kinase Signaling Pathway. Journal of Agricultural and Food Chemistry 63:7399-7404.

Zhang H, Li R, Liu W (2011) Effects of Chitin and Its Derivative Chitosan on Post harvest Decay of Fruits: A Review. International Journal of Molecular Sciences 12: 917-934. 